\title{
Investigating Instructors' Techniques to Develop EFL University Students Conversational Competence
}

\author{
Hussein A. Ahmed ${ }^{1}$, Husamuddin S. Mohammed ${ }^{2}$ \\ 1,2Department of English Language, University of Nawroz, Duhok, Kurdistan Region - Iraq
}

\begin{abstract}
The ever-growing need for good communication skills in English has created a huge demand for English teaching around the world. Millions of people today want to improve their command of English. And opportunities to learn English are provided in many different ways such as formal instruction, travelling, studying abroad, as well as through the media and the Internet. Such a worldwide demand for English has created an enormous demand for quality language teaching and language teaching materials and resources so as to meet learners' demanding goals. Learners want to be able to master English to a high level of accuracy and fluency through the acquisition of good English language skills since fluency in English is a prerequisite for success and advancement in many fields of employment in today's world. The present research attends to the techniques utilized by English as a foreign language (EFL) university instructors to develop their students' speaking skills. It hypothesizes that EFL university instructors use a variety of techniques to bring about such an objective. To bring about the aims of the research and validate the posed hypothesis, a 30-item questionnaire has been designed and distributed among all the instructors of conversation at the Depts. of English and Translation / University of Mosul during the second term of the academic year 2103-2014. The analysis of the data collected via the sample's responses to the questionnaire indicates that EFL instructors used indeed a variety of instructional techniques to develop their students' speaking skills. Hence the posed hypothesis has been accepted and duly a set of concluding remarks and recommendations have been put forward.
\end{abstract}

KEYWORDS : Instructors, EFL, Conversation.

\section{INTRODUCTION}

Learning to speak any new language is a difficult but not an impossible task. It is represented, in the main, by the acquisition of oral communicative competence, i.e. the ability to speak appropriately and smoothly with proper intonation, i.e. fluency. The latter is brought about when many language oral skills find their way for practice and learning in an EFL classroom. Yet, it

Academic Journal of Nawroz University

(AJNU) Volume 7, No 4 (2018).

Regular research paper : Published 8 December 2018

Corresponding author's e-mail : haa_1957@yahooo.com

Copyright $\odot 2017$ Hussein A. Ahmed Garagri ${ }^{1}$,

Husamuddin S. Mohammed ${ }^{2}$. This is an open access article

distributed under the Creative Commons Attribution

License. remains the teacher's task to manage such skills through the carrying out of a variety of instructional techniques and learning activities in such a way to guarantee the achievement of two important elements, namely comprehensible input and social interaction and duly the enhancement of students' speaking kills. This is so because human speech is a complex learned skill and is dependent on a number of memory and neurological functions, and most students often evaluate their success in language learning on the basis of how much they feel they have improved in their speaking proficiency. This is important as Richard (2006) further states that teachers' should focus their efforts on developing students' ability to speak by providing them with speaking activities that enable them to speak English since learning to speak is considered as the greatest challenge for all language learners. There are 
evident problems that characterize EFL university students' state in English conversation classes. In addition to improper knowledge of the principles of proper conversation, such as the start and end of a turn, or taking turns in advance, or breaking conversation off, many EFL university students suffer from some very broad problems represented generally by weak conversational competence, performance of oral language, and particularly by well performance of oral English, the use of Arabic words and structures in English and lack of understanding the target culture. Such a problematic phenomenon has been further complicated by some university students' assumption that learning to speak English can be achieved through mere knowledge of English sentence patterns and the filling in with proper vocabulary in the slots of such patterns. This has led to a further problem as students seem to be overly formal, rude, or awkward in their interactions in English; a point that can often be the root of cultural misunderstandings. Added to that, there is no solid theoretical basis for any systematic methodology for teaching conversation (Rühlemann, 2008) to the extent that there has been noticeable lacking of the information on which conversational skills or language input should be used (Dörnyei and Thurrell, 1994 : 40). It is hypothesized that "EFL university teachers of conversation use a variety of techniques to enhance their students' conversational competence". The present research aims, in the first place, at identifying the techniques used by EFL university teachers of conversation to develop their students' conversational competence. It further aims at shedding light on conversation as the main subject of discussion side by side with a number of subtopics that are closely related to it. The current research is confined to a sample of EFL university teachers of conversation at the Depts. of English / Colleges of Arts, Education and Basic Education and Dept. of Translation/ College of Arts / University of Mosul during the second term of the academic year 2013-2014. The current research is expected to be of importance to both EFL teachers and students as it attempts to identify the most efficient techniques to develop students' conversational competence. It is also considered as a seminal research study in terms of its tackling of the teaching of English conversation at university level especially through the probing of the techniques adopted by EFL university students of conversation to develop such a competence.

\section{Conversation : Definition and Characteristics}

Conversation is so intertwined with daily interactions that it is difficult to define. Also, because various fields of study have informed conversation, namely linguistics, psychology, anthropology, and sociology (Gumperz, 1999 : 98), it becomes harder to compile a concise yet comprehensive definition of conversation.
As such, conversation can better be identified and defined through the handling of its characteristics, its functions and its conditions (Kroeker, 2009 : 8). The Oxford English Dictionary defines conversation as the "manner of conducting oneself in the world or in society; behaviour, mode or course of life" or the "interchange of thoughts and words; familiar discourse or talk". Hymes cited in Richards (1980 : 414) states that conversation is "a type of speech event" distinct from lectures, discussions, interviews and courtroom trials. It is also cooperatively constructed, i.e. based on contributions, assumptions, expectations, and interpretations of the participants' utterances. Nunan (1999 : 228) states that conversation is a way to verbally communicate for mostly interpersonal and somewhat transactional purposes. It is, also, according to Cook (1989 : 87), a way to mark relationships, that suspends social distance, status, and power through linguistic neutrality, equality, sympathy, and antipathy. On her part, Donaldson (2011: 14-15) puts forward a number of characteristics of conversation. Quoting McCarthy and Carter (1995), Donaldson points out that conversation is spontaneous as no time is there to prepare a structural turn or completely pre-think a thought or plan for a next-turn. She, based on Cullen and Kuo (2007), and Jakobovits and Gordon (1980), states that conversation is generally person-oriented, face-to-face with a shared context, and highly interactive. With these features, the conversational context can vary greatly from moment to moment, and the participants must constantly adjust and respond to the immediate issues they face. Kroeker (2009: 8) adds that conversation is cooperative. As such, it is a negotiated, self-regulated process where the participants have equal rights to produce utterances. Additionally, conversation is social as it establishes rapport and mutual agreement, engages in phatic communication, maintains and modifies social identity and involves interpersonal skills (Thornbury and Slade, 2006 : 17). Put differently, conversation is socially motivated as participants tend to engage in conversation with those around them to facilitate social interaction, not to provide the information that transactional language requires (Donaldson, 2011 : 15). This is so because social interaction is necessary for daily life, and conversation is the language we use to mediate social relationships. A further characteristic of conversation is that it is multi-sensory. This entails paralinguistic features such as eye-contact, facial expressions, body language, tempo, pauses, voice quality changes, and pitch variation (Thornbury, 2005 : 9) which affect conversational flow. Finally, although conversation is often regarded as any oral production of a meaningful combination of words and phrases, it is the exchange of thoughts, feelings, opinions, and ideas, i.e. it requires a "true communication of ideas" (Eckard 
and Kearny, 1981 : 4 cited in Donaldson, $2011: 16$ ). Finally, Biber et al. (1999 : 1041-1051) identify some more characteristics of conversation by stating that conversation takes place in the spoken medium, in shared context and in real time; avoids elaboration or specification of meaning; and is interactive and as such expressive of politeness, emotion, and attitude.

\section{Approaches to Teaching Conversation}

It is a well-known undeniable fact that two main elements of conversation, namely accuracy and fluency come to the forefront the moment mentioning is made of teaching conversation. Both accuracy and fluency are the result of constant repetitive natural language use when a speaker engages in meaningful interaction and maintains comprehensible and ongoing communication despite limitations in his or her communicative competence. Richards (2006: 14) states that fluency is developed by natural meaningful use of language, achieving communication, using communication strategies, produce unpredictable language, and linking language use to context. Accuracy is also fostered through classroom use of language, formation of correct examples of language, practice of language out of context, practice of small samples of language, and controlled choice of language. In the current section, light will be shed on the approaches used for teaching conversation so as to bring about both accuracy and fluency on the part of the EFL students. These approaches are the Indirect Approach, Direct Approach and Awareness Raising Approach.

\section{The Indirect Approach}

The indirect approach is based on the idea that conversation competence will emerge from participating in interactive activities such as discussions, role-plays, information gaps, and problemsolving tasks (Dornyei and Thurrell, 1994 : 41; Kroeker, 2009 : 11). It entails the unconscious acquisition of language through comprehensible input and heavy practice of oral skills represented by different communicative activities that provide face-to-face interaction. The role of the instructor in this approach is to be a "manager...who knows how to encourage and give incentives" (Chang, 1975 : 126). The instructor is expected to bring knowledge and expertise to the class and to help the students in testing their newly acquired language skills and abilities. Activities typical of this approach are drills, i.e. whole-class repetition of utterances spoken aloud by the teacher and dialogue memorization.

\section{The Direct Approach}

The direct approach is based on a systematic conversation program of micro-skills, communication strategies, language input and processes that lead to fluent conversation (Kroeker, 2009 : 11). It stresses the explicit instruction of speaking by making learners be aware of the nature, systems and patterns of language through very specific input. In other words, learners are immersed in the language in the same way as when they learned their native language. As such, students are expected to participate in speaking activities trying to reproduce all the aspects of their daily life in sets as similar as possible to real contexts.

The Awareness-Raising Approach

Nolasco and Arthur (1987) stress learners' awareness of the way that native speakers achieve conversational competence. Accordingly, students are provided with direct instructions for the better observation of the different aspects of language. Eslami-Rasekh (2005 : 200) points out that "through awareness-raising activities, students acquire information about pragmatic aspects of language" as a means that facilitates students' transfer from their native language to the foreign language. On his part, Kasper (1997, quoted in ibid. : 201) suggests two kinds of activities, viz. activities aimed at raising students' pragmatic awareness, and activities offering opportunities for communicative practice. Finally, Hughes (2002) insists on the use of activities based on the rules of face-to-face interactions through which a closer and more conscious relation between the student and the new language he is learning is established. In addition to the three preceding approaches, Donaldson (2011 : 17-22) adds two more approaches, namely the Free Communication Approach, and the Conversation Norms Approach.

\section{The Free Communication Approach}

This approach views appropriate instruction in conversation through participation in activities such as role play, problem-solving tasks, information-gap activities, and language games. Additionally, warm-up exercises are generally used by teachers to help the students review important vocabulary and to ready their minds for the upcoming discussions. The instructor, as an 'organizer' here is expected to provide a wide variety of relevant topics for the students to discuss, and must plan ahead to anticipate the direction of the conversation so that he can supply supportive materials and vocabulary to enhance the discussion (Harper and Lively, 1986). Hughes (2002 : 4) concludes that within classroom interaction, students actively interact with both the teacher and other students, correcting each other's mistakes and offering suggestions.

\section{The Conversation Norms Approach}

This approach emphasizes authentic exchanges of ideas and incorporates a focus on form through the "micro skills, strategies, and processes" of the foreign language and systematically integrates language input to raise students' awareness of the foreign culture norms (Dörnyei and Thurrell, 1994 : 41). It recognizes the language learners' need to understand the more subtle 
issues of foreign language communication.

\section{Strategies to Develop Conversational Competence}

In an attempt to set up a sort of combination between the theoretical part of the topic mainly represented by the strategies used by teachers to develop their students' conversational competence, reference will be first made to a set of instructional strategies suggested by Xiaohong (1994), Richards (2006). Zhang (2008), and Emerson (n. d.) and so as to pave the way for their inclusion in the questionnaire prepared for collecting the required data :

Turn-taking demands students focusing attentively on what is going on so that the conversation goes smoothly. It is quite necessary to train the students how to pre-plan a turn; (2) take a turn; (3) interrupt a turn; (4) hold a turn; (5) pass a turn; (6) repair a turn; (7) and close.

Exchange generally includes two steps : initiation and answer. Conversational structural system model is made up of act, move (turn), exchange, transaction and interaction An exchange is composed of more than two moves (turns) (initiation and response).

Group Work entails students getting along with others. It can be translated into cooperative group work in the classroom so as to enhance students' growth in language, building on conversational skills they already possess and easing adaptation to school routines.

Games create experiences with language and ideas, and "experience is the glue that makes learning stick" (Emerson, n.d. : 120).

Songs are language-based. They are popular with all ages and can be successful throughout the grades.

Dramatization provides students with a variety of contextualized and scaffold activities that gradually involve more participation and more oral language proficiency. It is different from Role plays activities in which students are assigned roles and improvise a scene or exchange based on given information or clues. Word-guessing game : It is important to start from a simple point, i.e. to speak correctly in sentences before acquiring oral communicative competence.

Description aims to train students to speak in paragraphs, and to be able to make themselves understood.

Topic talking helps students put together a formal presentation by providing them with an outline or a few key words.

Familiarizing students with the nonlinguistic features of the language by (a) introducing cultural background knowledge, (b) Introducing pragmatic knowledge about the foreign language by enabling students to know when, where, and how to apply this knowledge to different contexts so as to arrive at natural, casual, and appropriate communication with native speakers.

Information-Gap Activities enable students to normally communicate in order to get information they do not possess. Richards (2006 : 17) states that more authentic communication is likely to occur in the classroom if students go beyond practice of language forms for their own sake and use their linguistic and communicative resources in order to obtain information.

Jigsaw Activities are based on the information-gap principle. Typically, the class is divided into groups and each group has part of the information needed to complete an activity. The class must fit the pieces together to complete the whole.

Task-Completion Activities represented by puzzles, games, map-reading, and other kinds of classroom tasks which focus on using one's language resources to complete a task.

Opinion-sharing activities where students compare values, opinions, or beliefs, such as a ranking task in which students list six qualities in order of importance.

Information-Transfer Activities require students to take information presented in one form, and represent it in a different form. An example is reading information about a subject and then representing it as a graph.

Reasoning-Gap Activities involve deriving some new information from given information through the process of inference, practical reasoning, etc.

\section{B. The Practical Part}

\section{Procedure and Data Collection :}

The procedure adopted in the present research is twofold. First, it is theoretical in terms of tackling a number of topics and subtopics that are relevant to the subject under discussion. Second, it is practical as a $30=i$ tem questionnaire of (30) items that stand for the main techniques for developing conversational competence has been administered to a sample of (8) EFL university teachers of Conversation at the different respective Depts. of English and Translation of the Colleges of the University of Mosul during the first term of the academic year 2013-2014 to investigate the techniques they adopt to develop their students' conversational competence. The respondents were asked to give responses to a (30-item) questionnaire designed by the researchers on the basis of the preceding related literature on the techniques suggested by Xiaohong (1994), Richards (2006). Zhang (2008), and Emerson (n. d.) and on the researchers' experience in teaching conversation at university level for many years. However, the researchers made some slight modification to the questionnaire, in the light of the suggestions put forward by the panel of jurors (See Appendix 1), to establish validity. There was no chance for piloting the questionnaire to prove its reliability due to the small main sample of the research $(8$ teachers of conversation). The respondents were supposed to give responses according to a scale of 5-options with a grade 
allocated for each option on analyzing the data as follows :

Figure (1) : Values Allocated to the Options of the Scale

\begin{tabular}{|c|c|}
\hline Option & $\begin{array}{c}\text { Value allocated on Analysis of } \\
\text { responses }\end{array}$ \\
\hline Always & 4 \\
\hline Often & 3 \\
\hline Sometimes & 2 \\
\hline Rarely & 1 \\
\hline Never & 0 \\
\hline
\end{tabular}

VI. The Population and The Sample of the research :

The population and the sample of the present research includes all the teachers of conversation (8 teachers) at all the concerned Depts. of the Colleges of the
University of Mosul, during the first term of the academic year 2013-2014.

VIII. The Model Adopted

The model adopted is an amalgamation of the techniques to develop conversational competence advocated by Xiaohong (1994), Richards (2006) and Zhang (2008). It has been adopted and set in a questionnaire form by the present researchers after modifications and suggestions put forward by the Jury Members.

\section{Data Analysis}

The data collected via the questionnaire administered to the sample selected for the current research were analyzed in terms of frequency, percentages, and the Weighted Arithmetic Means (WAM) of the recurrence of responses to each item. See Table (1) :

Table (1) : The Frequencies and WAMs of the Items of the Questionnaire According to the Sample's Responses

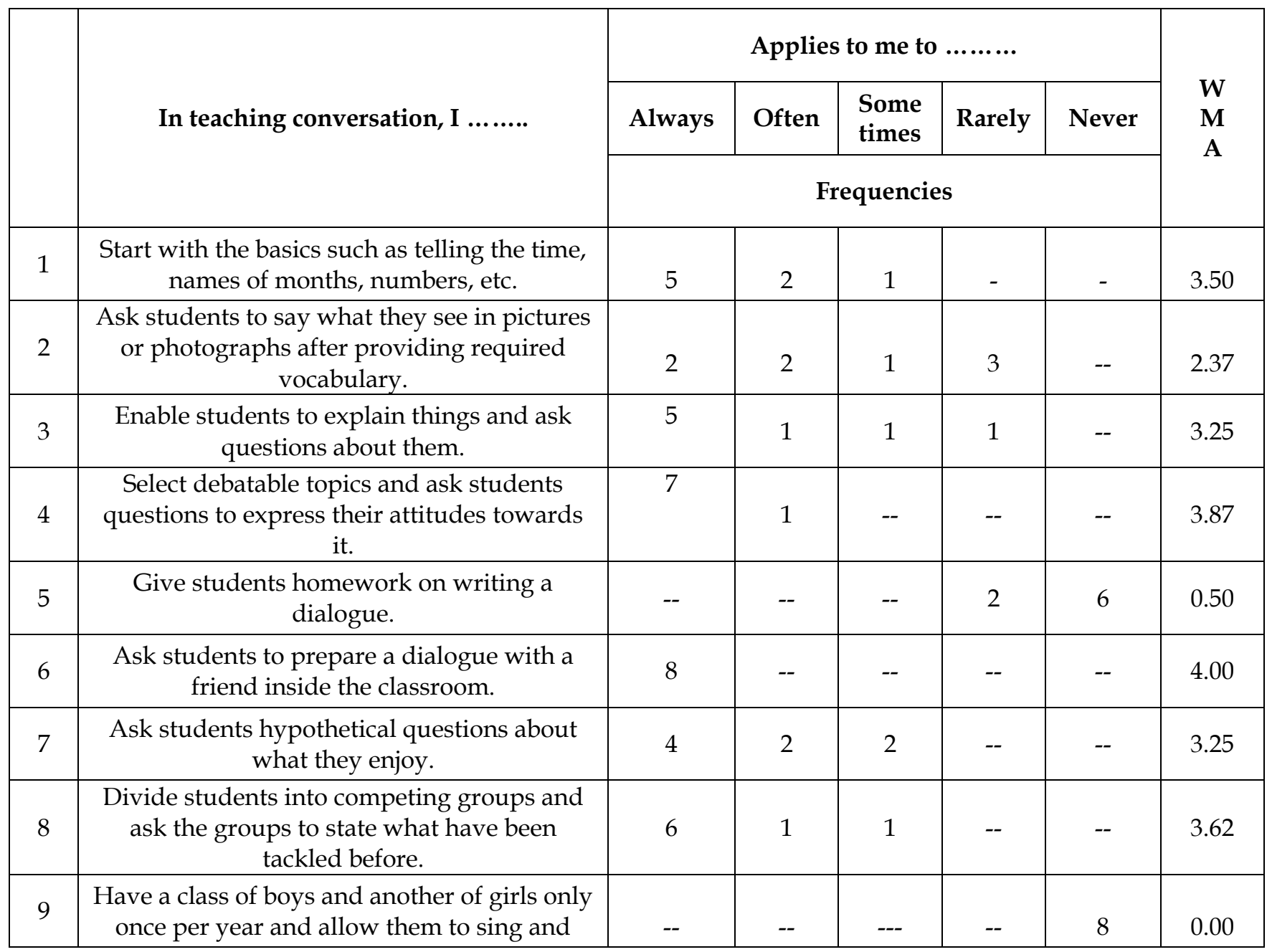




\begin{tabular}{|c|c|c|c|c|c|c|c|}
\hline & express themselves freely. & & & & & & \\
\hline 10 & $\begin{array}{l}\text { Write idioms and proverbs on the board as } \\
\text { topics for discussion. }\end{array}$ & 1 & 2 & 2 & 3 & -- & 2.125 \\
\hline 11 & $\begin{array}{l}\text { Create hypothetical critical situations and ask } \\
\text { students to think of solutions. }\end{array}$ & 1 & 1 & 1 & 3 & 2 & 1.50 \\
\hline 12 & $\begin{array}{l}\text { Show students videotapes and ask them to } \\
\text { comment on the topic or situation. }\end{array}$ & -- & 2 & 2 & 2 & 2 & 1.50 \\
\hline 13 & Hold discussions on some TV programmes. & 1 & 3 & 1 & 1 & 2 & 2.00 \\
\hline 14 & $\begin{array}{l}\text { Make students compare between certain } \\
\text { aspects of life in different cultures. }\end{array}$ & -- & 2 & 1 & 3 & 2 & 1.37 \\
\hline 15 & $\begin{array}{c}\text { Have lectures in the open air and ask } \\
\text { students to express their impressions and } \\
\text { reflections. }\end{array}$ & -- & -- & -- & 1 & 7 & 0.125 \\
\hline 16 & $\begin{array}{l}\text { Establish a friendly atmosphere where } \\
\text { students feel relaxed to express their ideas. }\end{array}$ & 6 & 2 & -- & -- & -- & 3.75 \\
\hline 17 & $\begin{array}{l}\text { Maintain a good relationship with all } \\
\text { students in the conversation lecture. }\end{array}$ & 4 & 5 & --- & -- & -- & 3.875 \\
\hline 18 & $\begin{array}{l}\text { Pose questions and ask students to provide } \\
\text { answers orally. }\end{array}$ & 7 & 1 & -- & -- & -- & 3.875 \\
\hline 19 & $\begin{array}{l}\text { Use encouraging expressions in response to } \\
\text { students' comments. }\end{array}$ & 8 & -- & -- & -- & -- & 4.00 \\
\hline 20 & $\begin{array}{l}\text { Avoid over-correction of pronunciation, } \\
\text { grammatical and stylistic mistakes. }\end{array}$ & 5 & 2 & 1 & -- & --- & 3.50 \\
\hline 21 & $\begin{array}{l}\text { Nominate single students to present topics } \\
\text { for discussion before the class. }\end{array}$ & 3 & 2 & 2 & 1 & --- & 2.875 \\
\hline 22 & Make students feel self-confident. & 5 & 2 & 1 & -- & --- & 3.50 \\
\hline 23 & $\begin{array}{c}\text { Give students the chance to suggest topics for } \\
\text { discussion. }\end{array}$ & 1 & 3 & 2 & 2 & --- & 2.375 \\
\hline 24 & $\begin{array}{l}\text { Encourage students to visit the worldwide } \\
\text { web and download materials from } \\
\text { EFL/speaking websites. }\end{array}$ & 1 & 1 & 3 & 1 & 2 & 1.75 \\
\hline 25 & Ask students to play roles. & 4 & 4 & -- & -- & -- & 3.50 \\
\hline 26 & $\begin{array}{l}\text { Use the lap-top to make students listen to } \\
\text { conversations by native speakers. }\end{array}$ & 8 & -- & -- & -- & -- & 4.00 \\
\hline 27 & $\begin{array}{l}\text { Use checkpoints to assess students } \\
\text { conversational development from time to } \\
\text { time. }\end{array}$ & 6 & 2 & -- & -- & -- & 3.75 \\
\hline 28 & $\begin{array}{l}\text { Provide students with necessary vocabulary } \\
\text { items to maintain the flow of communication. }\end{array}$ & 2 & 2 & 3 & 1 & -- & 2.625 \\
\hline 29 & $\begin{array}{l}\text { Correct students' grammatical errors when } \\
\text { they affect comprehension of the messages } \\
\text { conveyed. }\end{array}$ & 4 & 3 & 1 & -- & -- & 3.375 \\
\hline 30 & $\begin{array}{l}\text { Use brainstorming questions such as : "What } \\
\text { is the first thing that comes to you when I say } \\
\text { "London"'?? }\end{array}$ & 1 & 2 & 3 & 2 & --- & 2.25 \\
\hline
\end{tabular}


For better understanding of the contents of Table (1), the items will be ranked according to their mean scores from the highest to the lowest. See Table (2) :

Table (2) : The Items of the Questionnaire Ranked According to their Mean Scores from the Highest to the Lowest

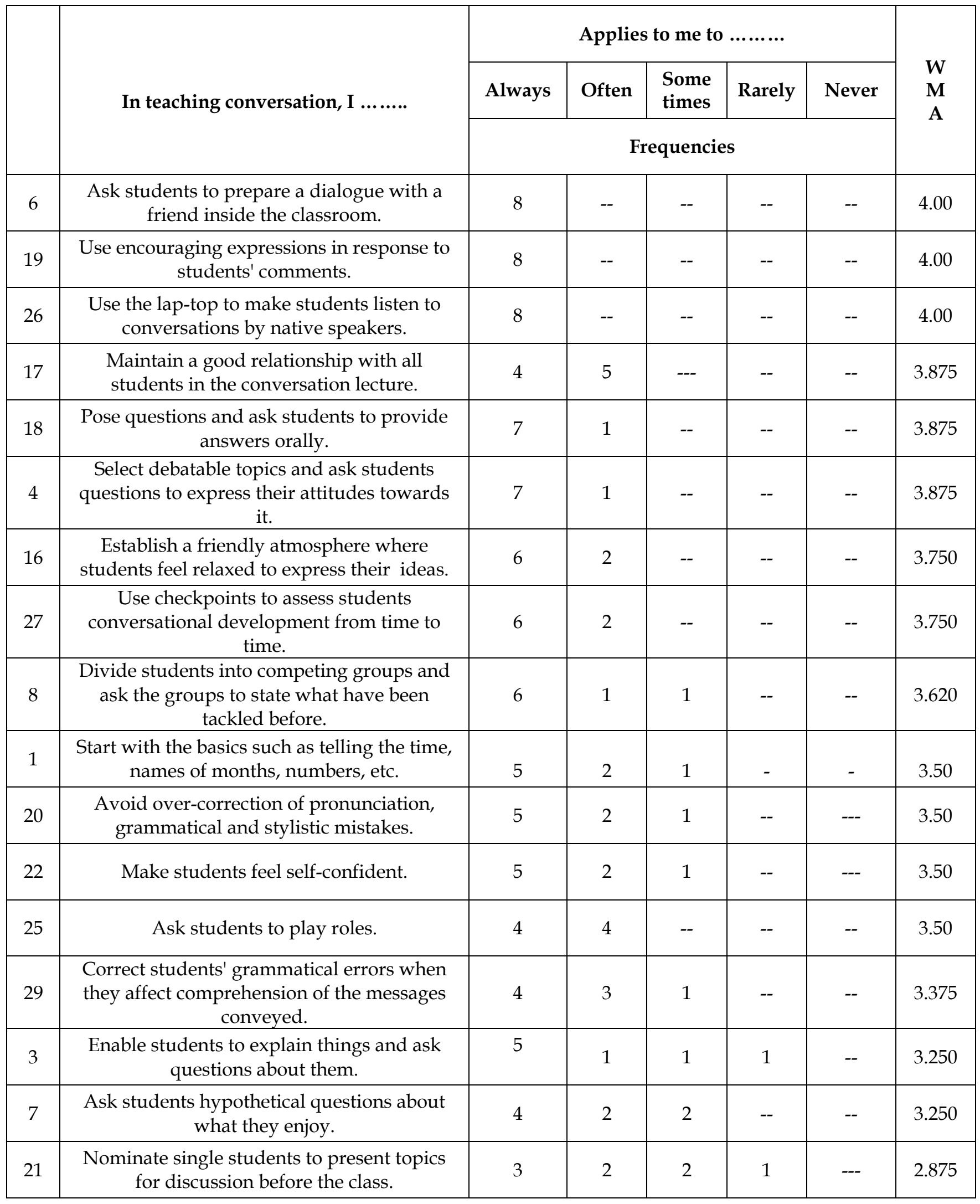




\begin{tabular}{|c|c|c|c|c|c|c|c|}
\hline 28 & $\begin{array}{l}\text { Provide students with necessary vocabulary } \\
\text { items to maintain the flow of communication. }\end{array}$ & 2 & 2 & 3 & 1 & -- & 2.625 \\
\hline 23 & $\begin{array}{c}\text { Give students the chance to suggest topics for } \\
\text { discussion. }\end{array}$ & 1 & 3 & 2 & 2 & --- & 2.375 \\
\hline 2 & $\begin{array}{c}\text { Ask students to say what they see in pictures } \\
\text { or photographs after providing required } \\
\text { vocabulary. }\end{array}$ & 2 & 2 & 1 & 3 & -- & 2.375 \\
\hline 30 & $\begin{array}{l}\text { Use brainstorming questions such as: "What } \\
\text { is the first thing that comes to you when I say } \\
\text { "London"'?. }\end{array}$ & 1 & 2 & 3 & 2 & --- & 2.25 \\
\hline 10 & $\begin{array}{l}\text { Write idioms and proverbs on the board as } \\
\text { topics for discussion. }\end{array}$ & 1 & 2 & 2 & 3 & -- & 2.125 \\
\hline 13 & Hold discussions on some TV programmes. & 1 & 3 & 1 & 1 & 2 & 2.00 \\
\hline 24 & $\begin{array}{l}\text { Encourage students to visit the worldwide } \\
\text { web and download materials from } \\
\text { EFL/speaking websites. }\end{array}$ & 1 & 1 & 3 & 1 & 2 & 1.75 \\
\hline 12 & $\begin{array}{l}\text { Show students videotapes and ask them to } \\
\text { comment on the topic or situation. }\end{array}$ & -- & 2 & 2 & 2 & 2 & 1.50 \\
\hline 11 & $\begin{array}{l}\text { Create hypothetical critical situations and ask } \\
\text { students to think of solutions. }\end{array}$ & 1 & 1 & 1 & 3 & 2 & 1.50 \\
\hline 14 & $\begin{array}{l}\text { Make students compare between certain } \\
\text { aspects of life in different cultures. }\end{array}$ & -- & 2 & 1 & 3 & 2 & 1.37 \\
\hline 15 & $\begin{array}{c}\text { Have lectures in the open air and ask } \\
\text { students to express their impressions and } \\
\text { reflections. }\end{array}$ & -- & -- & -- & 1 & 7 & 0.125 \\
\hline 5 & $\begin{array}{c}\text { Give students homework on writing a } \\
\text { dialogue. }\end{array}$ & -- & -- & -- & 2 & 6 & 0.50 \\
\hline 9 & $\begin{array}{l}\text { Have a class of boys and another of girls only } \\
\text { once per year and allow them to sing and } \\
\text { express themselves freely. }\end{array}$ & -- & -- & --- & -- & 8 & 0.00 \\
\hline
\end{tabular}

\section{Discussion of Results}

Since the scale set for measuring the responses of EFL University teachers of conversation ranges from (0) as the lowest point and (4) as a highest point, the items of the questionnaire will be dealt with in terms of the values obtained for each set as follows :

Figure (2) : Distribution of the Items of the

Questionnaire According to the Values Obtained

\begin{tabular}{|c|c|}
\hline Items & Values Obtained \\
\hline $\begin{array}{c}6,19,26,17,18,4,16,27,8,1, \\
20,22,25,29,3,7\end{array}$ & 3.00 to 4.00 \\
\hline $21,28,23,3,30,10,13$ & 2.00 to 2.99 \\
\hline $24,12,11,14,15,5$ & 1.00 to 1.99 \\
\hline
\end{tabular}

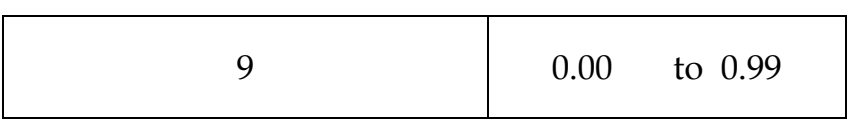

1. Sixteen items of the questionnaire have obtained values ranging between 3.00 and 4.00 . This outlines the samples heavy use of these techniques to develop their students' conversational competence.

Three items out of these sixteen items, namely items Six. Asking students to prepare a dialogue with a friend inside the classroom, nineteen. Using encouraging expressions in response to students' comments, and twenty six. Using the lap-top to make students listen to conversations by native speakers, have obtained The full value, i.e. 4 which means that these three techniques are used by the whole sample.

The other thirteen items, namely items 17, 18, 4, 16, 27, $8,1,20,22,25,29,3$, and 7 have obtained mean values ranging between (3.875) as the highest value and (3.25) as the lowest value. Again such values outline the heavy use of these techniques by the EFL university 
teachers of conversation. It is worthy to note that this set of items that has obtained the highest values is the only other sets that subsumes twelve academic, i.e. instructional techniques and four psychological techniques, namely items 16, 17, 19 and 22 as teachers had found in encouraging students, building their selfconfidence, setting good relations with them, and providing relaxing classroom atmospheres as positive techniques to develop conversational competence in EFL university classes.

2. Seven items, namely $21,28,23,3,30,10$, and 13 have obtained mean values ranging between (2.875) as the highest value and (2.00) as the lowest value. Since these values, except that for item 13, namely (2.00) are above the mid-point of the range of the values set for measuring the sample's responses, this indicates a moderate use of these techniques by EFL university teachers of conversation.

3. Six items, namely $24,12,11,14,15$, and 5 have obtained mean values below the mid-value (2), i.e. ranging between (1.75) as the highest value and (0.50) as the lowest value. It can be deduced that EFL university teachers make a minimum use of these items in their conversation classes.

4. One item, namely item 9. Having a class of boys and another of girls only once per year and allow them to sing and express themselves freely, have obtained a (0.00) value. This indicates that no teacher of conversation at university level makes use of this item in developing EFL students' conversational competence. This may be due to certain cultural or educational restrictions that eliminate the use of such a technique. Accordingly, the hypothesis set at the beginning of this research which states that "EFL university teachers of conversation use a variety of techniques to enhance their students' conversational competence" is accepted.

\section{Conclusion}

The process of teaching and learning EFL almost always does not go on in a smooth manner. Factors that hamper the process usually appear here and there. They are stemmed from varied sources, represented in the main by the three pillars of the educational process, namely teachers, learners and teaching materials. The topic under investigation in the current research is multifaceted, i.e. it ascribes the negative outcomes of the process to all the pillars already referred to with no exception. Students' failure to manage their required involvement in the ongoing conversational tasks can be due to teachers either improper handling of the instructional techniques or their lacking of the required knowledge about them. Added to that, the strategies or the techniques used by teachers may be wrongly chosen and improperly implemented due to teachers' lacking of experience or knowledge. Finally, students, due to a bulk of factors that are beyond the limits of the current research, may not be responsive and do not get involved in the teaching activities. For all the reasons stated above, this research has been launched to investigate the investigate the techniques used by EFL teachers in teaching conversation at University level. The results show that EFL university teachers of conversation make use of a variety of techniques to develop their students' conversational competence.

\section{Recommendations}

1. Teachers of conversation are supposed to be knowledgeable of the different aspects of conversational language since learners have different linguistic backgrounds and are differently knowledgeable as far as their cultural backgrounds are concerned.

2. Teachers of conversation are supposed to be aware of the purposes behind students' studying at large and the studying of conversation in particular. By so doing, they can successfully choose the proper activities to be used at the proper time and for the proper caliber of students.

3. Teacher of conversation should attend to both accuracy and fluency simultaneously though the time allotted to fluency should surely outweigh that for accuracy. Richards (2006:23) states that grammar is not taught in isolation but often arises out of a communicative task, thus creating a need for specific items of grammar. Students might carry out a task and then reflect on some of the linguistic characteristics of their performance.

4. To create learners' need for communication, interaction, and negotiation of meaning, teachers of conversation are supposed to use activities such as problem solving, information sharing, and role play.

5. Students should be taught to be personalized so as to apply what they have learned to their own lives.

\section{References}

1. Biber, D. et al. (1999). Longman Grammar of Spoken and Written English. Essex. Pearson Education Ltd.

2. Chang, A. (1975). "Semi-free conversation : A beachhead leading to liberated spontaneous conversation". Journal of the Association of Teachers of Japanese, Vol.10, nos. 2/3, 119-132.

3.Cook, G. (1989). Discourse. Oxford : Oxford University Press.

4.Cullen, R., \& Kuo, I. (2007). "Spoken grammar and ELT course materials : A missing link?" TESOL Quarterly, Vol.41, No.2, 361-386.

5.Donaldson, R. M. (2011). Teaching Foreign Language Conversation : A Conversation Norm Approach (Unpublished M. A. Thesis, The Faculty of California State University, Chico).

6.Dörnyei, Z., \& Thurrell, S. (1994). “Teaching conversational skills intensively : Course content and 
rationale". ELT Journal, Vol.4, no.1, 40-49.

7.Eslami-Rasekh, Z. (2005). "An international journal for teachers of English to speakers of other languages". ELT Journal, 59, 199-208.

8.Gumperz, J. (1999) "Sociocultural Knowledge in Conversational Inference" in Jaworski, A. and Coupland, N. (eds.) The Discourse Reader. Oxon : Routledge.

9.Harper, J., \& Lively, M. (1986). “Techniques and materials for conversation in the foreign language classroom". Retrieved from ERIC Database.

10. Hughes, R. (2002). Teaching and researching speaking. London : Longman.

11. Jakobovits, L. and Gordon, B. (1980). "Language teaching vs. the teaching of talk". International Journal of Psycholinguistics, Vol.6, no.4, 5-22.

12. Kroeker, R. H. (2009). The Reality of English Conversation Classes : A Study in a South Korean University.(Unpublished Ph.D. Dissertation, University of Birmingham)

13. McCarthy, M. and Carter, R. (1995). Spoken grammar : What is it and how can we teach it. ELT Journal, Vol.49, No.3, 207-218.

14. Nolasco, R. and Arthur, L. (1987). Conversation. Oxford: Oxford University Press..

15. Nunan, D, (1999). Second Language Teaching and Learning. Boston : Heinle and Heinle Publishers.

16. Richard, J. C. (2006). "Developing Classroom Speaking Activities : From Theories to Practice". Journal Watch. Vol.28, No.2.

17. Richards, J. (1980). 'Conversation.' TESOL
Quarterly Vol.14, no.4, 413-432.

18. Richards, J. C. (2008). Communicative Language Teaching Today. Cambridge : Cambridge University Press.

19. Rühlemann, C. (2008). "A register approach to teaching conversation : Farewell to standard English?" Applied Linguistics, Vol. 29, No.4, 672-693.

20. Thornbury, S. (2005). How to Teach Speaking.

Essex : Pearson Longman

21. Thornbury, S. and Slade, D. (2006). Conversation : From Description to Pedagogy. Cambridge : Cambridge University Press.

22. Xiaohong, D. (1994). "Developing Oral Communicative Competence among English Majors at the Intermediate Level". English Teaching Forum, Vol.3, No.4.

23. Zhang, Z.(2008.) "Discourse Analysis and Cultivation of Conversational Competence in English Class", in International Education Studies, Vol.8, No. 3, 60-75.

Appendix

Questionnaire

Dear Teacher of Conversation :

The researchers are investigating "Teachers' Techniques to Develop EFL University Students' Conversational Competence". Would you please give your frank and correct answers to the items of the following questionnaire by ticking $(\sqrt{ })$ in the square of the option, opposite to each item, which best applies to you. Many thanks for your cooperation.

\begin{tabular}{|c|c|c|c|c|c|c|}
\hline \multicolumn{7}{|c|}{ Appendix } \\
\hline \multirow{2}{*}{ SN } & \multirow{2}{*}{ In teaching conversation, I ........ } & \multicolumn{5}{|c|}{ Applies to me to ......... } \\
\hline & & Always & Often & $\begin{array}{l}\text { Some } \\
\text { times }\end{array}$ & Rarely & Never \\
\hline 1 & $\begin{array}{l}\text { Start with the basics such as telling the time, names of } \\
\text { months, numbers, etc. }\end{array}$ & & & & & \\
\hline 2 & $\begin{array}{l}\text { Ask students to say what they see in pictures or } \\
\text { photographs after providing required vocabulary. }\end{array}$ & & & & & \\
\hline 3 & $\begin{array}{c}\text { Enable students to explain things and ask questions about } \\
\text { them. }\end{array}$ & & & & & \\
\hline 4 & $\begin{array}{l}\text { Select debatable topics and ask students questions to } \\
\text { express their attitudes towards it. }\end{array}$ & & & & & \\
\hline 5 & Give students homework on writing a dialogue. & & & & & \\
\hline 6 & $\begin{array}{l}\text { Ask students to prepare a dialogue with a friend inside the } \\
\text { classroom. }\end{array}$ & & & & & \\
\hline 7 & $\begin{array}{c}\text { Ask students hypothetical questions about what they } \\
\text { enjoy. }\end{array}$ & & & & & \\
\hline
\end{tabular}




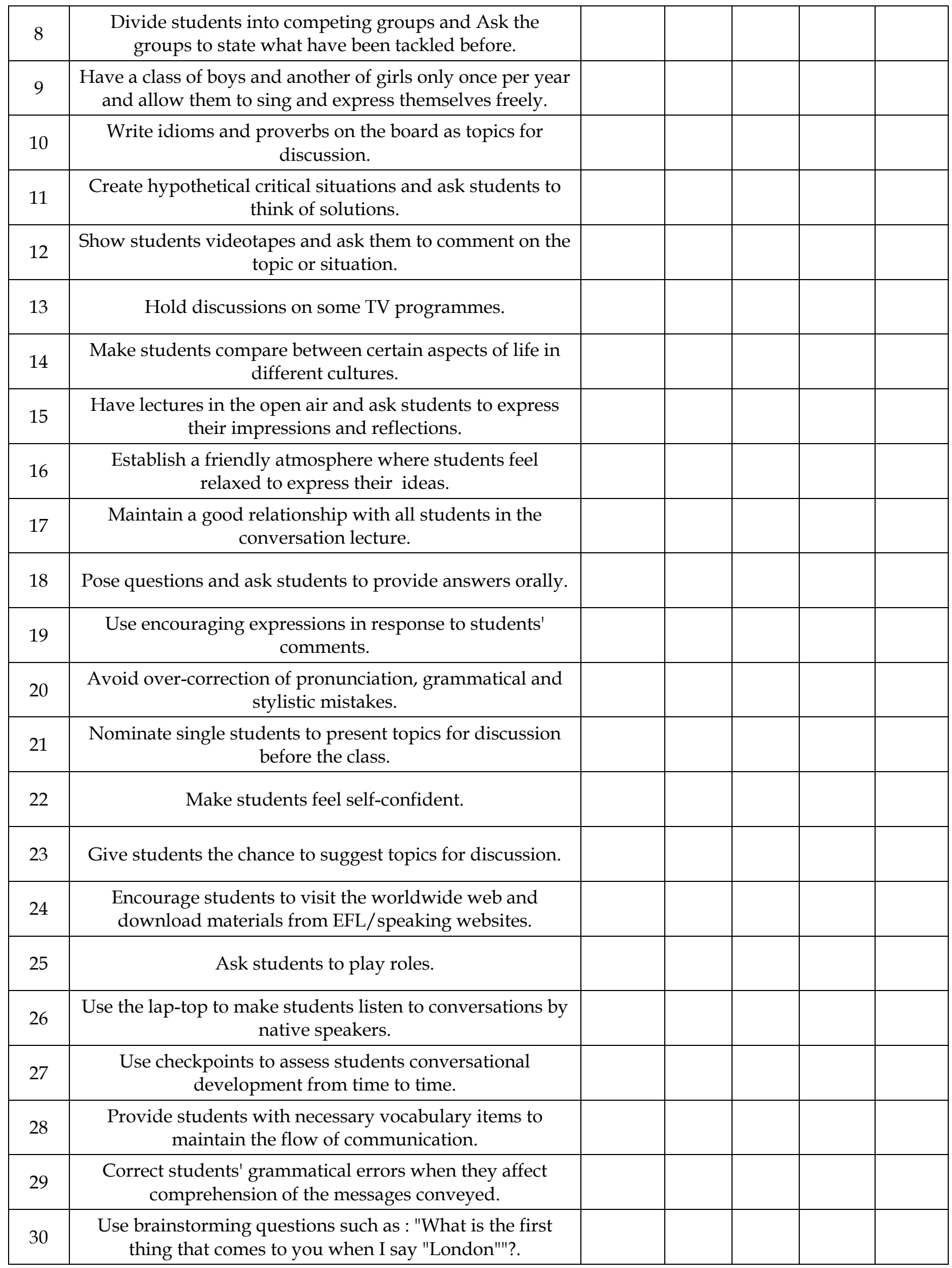

